\title{
David Ing
}

\section{Design Flaws and Service System Breakdowns Learning from Systems Thinking}

\begin{abstract}
In what ways might systems thinking be helpful to designers? In the 21st century, the types of projects designers have engaged have expanded to include service systems. Service systems are typically composites of mechanisms, organisms, human beings and ecologies. Systems thinking is a perspective with theories, methods and practices that enables transcending disciplinary boundaries. Application of systems thinking in designing a service system can aid in surfacing potential flaws and/or anticipating future breakdowns in functions, structures and/or processes. Designers and systems thinkers should work together to improve the nature of service systems. As a starter set into these conversations, seven conditions are proposed as starting contexts. These conditions are not presented as rigourously defined or as exhaustive, but as an entry point into future joint engagement.
\end{abstract}

Keywords: systems thinking, reframing, service systems, breakdowns

\section{Introduction}

The training of designers, either implicitly or explicitly, commonly involves some concepts with a long tradition in systems thinking. Much of the body of knowledge for systems thinking is rooted in the pre-Internet, pre-globalization, pre-climate-change period of the 1970s and 1980s (Ing, 2013). Designers may benefit by engaging with the contemporary body of knowledge on systems thinking with researchers and practitioners active in the 21 st century.

This article proposes ongoing engagement between designers and systems thinkers in a continuing collaboration. As an entry to that engagement, three questions are explored:

1. How have design thinking and systems thinking evolved?

2. In which ways might designers be helped by (advances in) the systems sciences?

3. Where might collaborations with systems thinkers naturally co-develop?

Collaborations between designers and systems thinkers may be formalized as inquiring systems. "Inquiry is an activity that produces knowledge" (Churchman, 1971, p. 8). The directions in which designers find development productive might offer an early conversation.

\section{How Have Design Thinking and Systems Thinking Evolved?}

Research into designerly ways of knowing and thinking includes citations to work familiar to most systems thinkers, e.g. Donald Schön, Horst Rittel, and Herbert Simon (Cross, 1982, 2001, 2007). The popularization of design thinking has led to proposals of how that perspective might be complemented by systems thinking, and a variety of perspectives abound. For our purposes, authentic (strong) systems thinking may be contrasted with espoused (weak) systems thinking on the basis of individual and peer disciplinary development. While systems thinking is a broad domain with many applications to design knowledge, designers may be particularly interested in the rise of one of its fields, service systems science, over the past decade. 


\subsection{Design thinking may be complemented by a long(er) tradition of systems thinking}

Design thinking - featuring three spaces of inspiration, ideation and implementation, in addition to characteristics of empathy, integrative thinking, optimism, experimentation and collaboration - has been popularized to managerial audiences (Brown, 2008). A longer perspective sees three generations of design:

- A first generation of design, where: the act of designing is by "designers"; professionals hold the knowledge critical to design; after the design has been created, there is no obligation to go further, and designs are "thrown over the wall" to contractors and users.

- A second generation of design, where: the need for collaboration amongst designers and external perspectives to guide them is recognized; inputs is welcomed from many stakeholders, including users; and the design team observes and interacts with a larger system environment; and

- A third (proposed) generation of design where: stakeholders are the designers; people are allowed to plan for themselves; the design facilitator creates an environment where differing views are honoured within the context of the larger system; and "authentic engagement" taps the creative energy of every participant.

The third generation is proposed to overcome two risks in the second generation: (i) an emphasis of the perspectives coming from the parts may miss the perspective of the whole; and (ii) there may be unintended consequences that emerge with parts are missed, so that a coherent whole does not result (Pourdehnad, Wexler, \& Wilson, 2011). They find that "An integrated approach to problem resolution requires design thinkers to expand their understanding of good systems design principles with a purposeful consideration of the social systems they are working within." This position highlights two ideas central to systems thinking, the engagement of a social system and the function of purpose.

\subsection{Authentic systems thinking contrasted with espoused systems thinking}

While many individuals may espouse themselves to be systems thinkers, it is not uncommon for them to miss the leading idea of the expansion of systems to larger wholes, in an overemphasis of analysis, the reduction of a system into its parts.

Systems thinking is a perspective on parts, wholes, and their relations (Ing, 2013). The most basic concepts of systems thinking are function, structure and process, as shown in Figure 1 . 


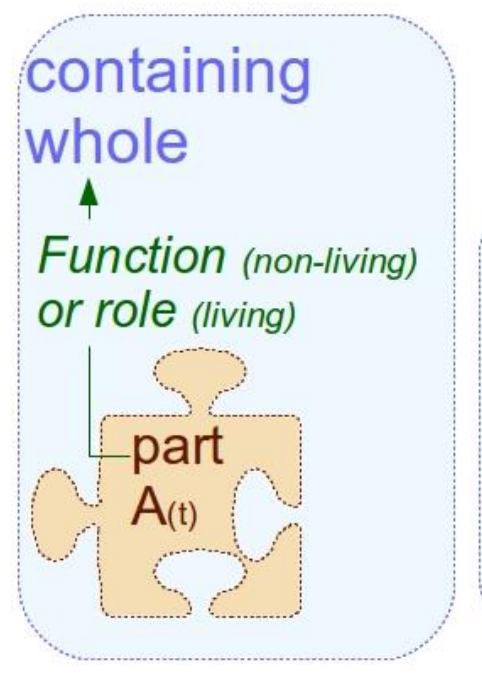

Function "contribution of the part to the whole"
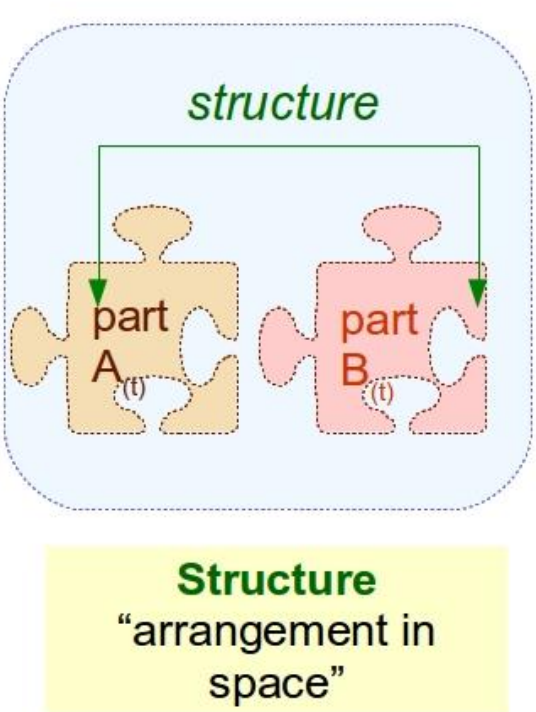

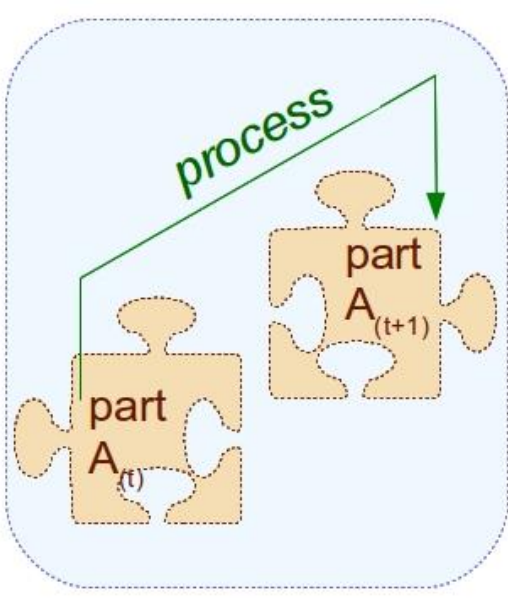

Process

"arrangement in time"

Figure 1: Function, structure, process

- Function is a contribution of a part to its containing whole. The relation is between a living part (e.g. a person) and a whole (e.g. an organization) is generally labelled as a role, rather than a function.

- Structure is an arrangement in space. That arrangement could be between two or more parts, or two or more wholes.

- Process is an arrangement in time. A part may persist through time, or evolve (Gharajedaghi, 2007).

In authentic systems thinking, synthesis precedes analysis. Synthesis is putting things together. Analysis is taking things apart. The function, as the relation between the part and the containing whole, is emphasized.

1. Identify a containing whole (system) of which the thing to be explained is a part.

2. Explain the behaviour or properties of the containing whole.

3. Then explain the behaviour or properties of the thing to the explained in terms of its role(s) or function(s) within its containing whole (Ackoff, 1981).

Non-authentic (weak) espoused systems thinkers gravitate towards analysis, often missing the context of the containing whole.

\subsection{Service systems thinking values service through a systems thinking perspective}

Amongst the community of systems thinkers, the significance of social systems - as distinct from mechanistic systems and biological systems - rose in the 1970s and 1980s, with the recognition of distinct features (e.g. human will). The appreciation of coproduction of value in systems developed in the 1990s (Normann \& Ramirez, 1994; Normann, 2001). Over the past decade, an appreciation for systems thinking for understanding service science has risen. 
A service system can be defined as a dynamic configuration of resources (people, technology, organisations and shared information) that creates and delivers value between the provider and the customer through service (IfM \& IBM, 2008).

Service systems are not new; the perspective of service systems thinking emphasizes value over production. Designers are increasingly become involved with the service systems that support human civilization in technical, organizational and socio-political forms, as listed in Table 1:

Table 1: Thirteen service systems, and the school grades in which they might be studied

\begin{tabular}{|c|l|c|}
\hline $\begin{array}{c}\text { Systems that move, store, } \\
\text { harvest, process }\end{array}$ & Transportation & $\mathrm{K}$ \\
\hline & Water and waste management & 1 \\
\hline & Food and global supply chains & 2 \\
\hline & Energy and energy grid & 3 \\
\hline & Information and communications (ICT) infrastructure & 4 \\
\hline $\begin{array}{c}\text { Systems that enable healthy, } \\
\text { wealthy and wise people }\end{array}$ & Buildings and construction & 5 \\
\hline & Banking and finance & 6 \\
\hline & Retail and hospitality & 7 \\
\hline & Healthcare & 8 \\
\hline & Education (including universities) & 9 \\
\hline & Government (cities) & 10 \\
\hline & Government (regions / states) & 11 \\
\hline & Government (nations) & 12 \\
\hline
\end{tabular}

- Systems that move, store, harvest and process include transportation, water and waste management, food and global supply chain, energy and energy grid, and information and communications (ICT) infrastructure;

- Systems that enable healthy, wealthy and wise people include building and construction, banking and finance, retail and hospitality, healthcare and education (including universities);

- Systems that govern include the governments of cities, the governments of regions and states, and the governments of nations (Spohrer \& Maglio, 2010).

These service systems are omnipresent in our everyday life. The ordering of the list is roughly from the more concrete to the more abstract, and could each serve as a focal point for study for children, from kindergarten to Grade 12.

Dysfunctional and inefficiencies in these systems of systems - with healthcare, education, government and safety, building and transport infrastructure as the most significant, are seen as a $\$ 4$ trillion challenge for the world (IBM, 2010). Designers are now being asked to work on transforming these legacy systems. 


\section{How Might Designers be Helped by (Advances in) the Systems Sciences?}

Designers may take iterative approaches to creating and improving alternative solutions. Service systems, however, may present the challenges of "wicked problems" that are illdefined, complex and constantly changing (Rittel \& Webber, 1973). The challenge may not just a problem to be solved, but instead a problematique - a system of problems that requires dissolving (Christakis, 2006).

The development of systems thinking continues to progress in the systems sciences, where multiple perspectives and transdisciplinary inquiries continue. Designers may be unfamiliar with some of the advances in knowledge gained over the past two decades. Flaws in the design of service system might be surfaced by conditions that have previously been recognized as patterns through systems thinking. Seven conditions are outlined below, as appetizers to encourage further research and dialogue. The number of conditions was arbitrarily chosen as seven, at the maximum capacity of cognitive load (i.e. Miller's number, $7 \pm 2$ ). In an interactive setting, a group could be led to cover a broader body of knowledge, with each participant producing his or her own personal list of 7 .

\subsection{Activity Package Mismatch: Theory of the Offering}

In interactions between customers (or clients or beneficiaries) and suppliers, there may be mismatches in expectations on outcomes. Offerings are three-dimension activity packages with physical content, service content and people content (Ramirez \& Wallin, 2000), depicted in Figure 2.

An offering may be an output (i.e. produced by one or more suppliers for the customer) or an input (i.e. coproduced by parties acting together). Customer value can be created through transactions, or through relationship. This leads to four types of logic, with:

- Industrial logic, with offering as output and customer value through transactions, e.g. delivery of an automobile from a factory;

- Self-service logic, with offering as input and customer value through transactions, e.g. an automated teller machine where the funds cannot be delivered unless the requester interacts with a machine;

- Service logic, with offering as output and customer value through relationship, e.g. a luxury hotel where customers are remembered from prior stays, so that amenities are prepared in advance; and

- Partnership logic, with offering as input and customer value through relationship, e.g. a joint venture technology development alliance where industry standards continue to evolve, so that each party brings unique inputs for collaboration, and resulting outputs are not guaranteed. 

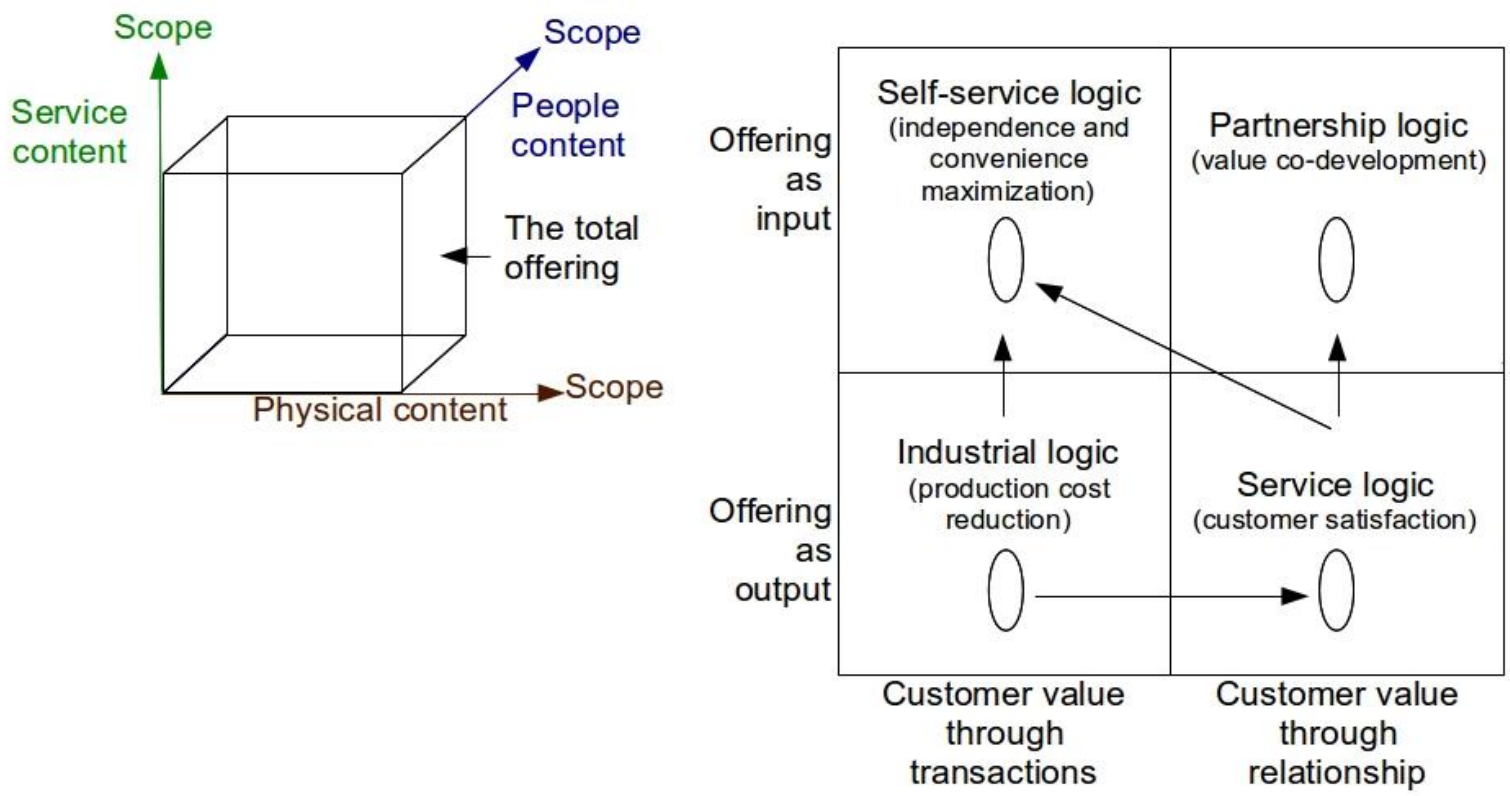

Figure 2: Theory of the Offering

Breakdowns can occur when all parties do not have a shared understanding about the shape of the activity package.

- One party could have the perspective that customer value is produced freshly for each and every transaction (e.g. we keep costs low by giving the same output for every customer every time), while another party sees customer value in an ongoing relationship (e.g. yes, sorry that things didn't work out this time, we can make it up the next time). Commonly, when contracts fail, recourse is not exercised and parties work out problems through negotiated order (Macaulay, 1963; Parhankangas, Ing, Hawk, Dane, \& Kosits, 2005).

- One party could have the perspective that an offering is an output (e.g. this recorded music is a performance that I can listen to, again and again), while another has the perspective that the offering is an input (e.g. this recorded music gives me samples that I can remix into my own performances).

Since a supplier could offer a variety of a different activity package to each different customer, this unit of analysis provides a foundation for a theory of the offering (Normann \& Ramirez, 1989).

\subsection{Coordination Fumble: Language Action Perspective}

In cooperative work, the language action perspective sees organizations as networks of directives and commissives (Winograd \& Flores, 1986; Winograd, 1986, 2006). With a directive, a speaker asks for a (future) performance of some action by the hearer. With a commissive, a speaker becomes committed to the future performance of an action. The network of speech acts - requests, counters, acceptances, promises, assertions, declarations constitute a conversation for action, shown in Figure 3. 


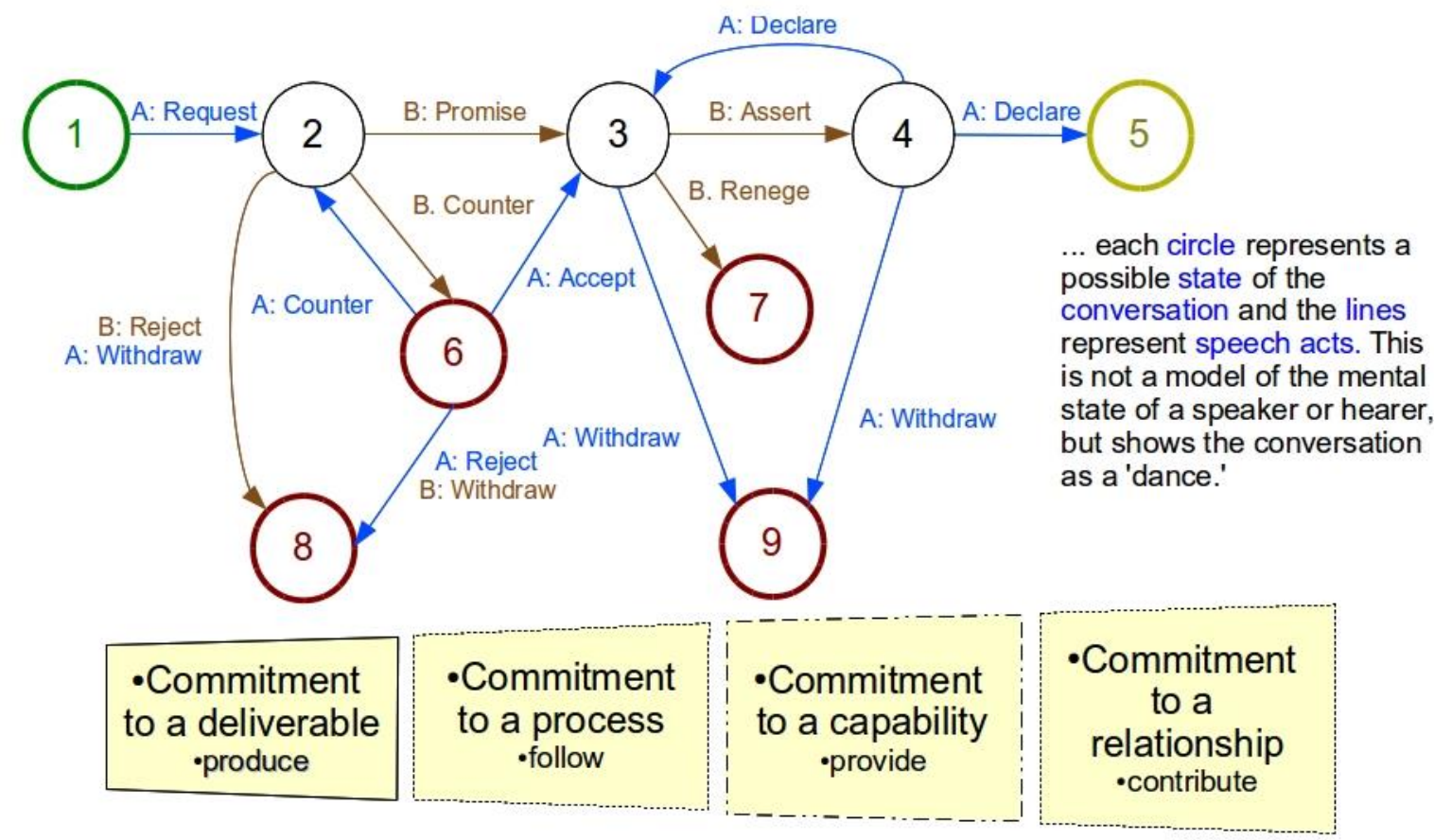

Figure 3: Language Action Perspective

Individuals less skilled in managing their speech acts may lead to failures in language action. Additionally, breakdowns may occur when unanticipated troubles arise, and commitments are not renegotiated in consideration of the new conditions.

In further detailing the language action that occurs in service systems, four types of commitments are suggested:

- Commitments to produce a deliverable (e.g. an output on a specified date - a house on closing day);

- Commitments to follow a process (e.g. roles and procedures for execution - legal protocols where standardized steps are followed);

- Commitment to provide a capability (e.g. an expected level of resource - the number of call centre operations answering telephones on a given day); or

- Commitments to contribute to a relationship (e.g. efforts to maintain a social arrangement with an associated - meeting a friend to share time together) (Ing, 2008).

A coordination fumble can occur when parties have different impressions of commitments made (e.g. a customer expects a tangible deliverable on a date, whereas the supplier provides time and materials over a period). The fumble can be exacerbated as each individual makes plans and commitments with others, based on the presumption of successful attainment of inputs committed to him or her. If the service system has alerts that a fumble has occurred or is about to happen, recovery or remediation of the breakdown may be possible. 


\subsection{Change Target Discord: Reactivism, inactivism, preactivism, interactivism}

When an intervention to change a service system is to be conducted, stakeholders may have different views on the preferred design. The orientations towards change may be described in one of four dispositions, depicted in Figure 4:
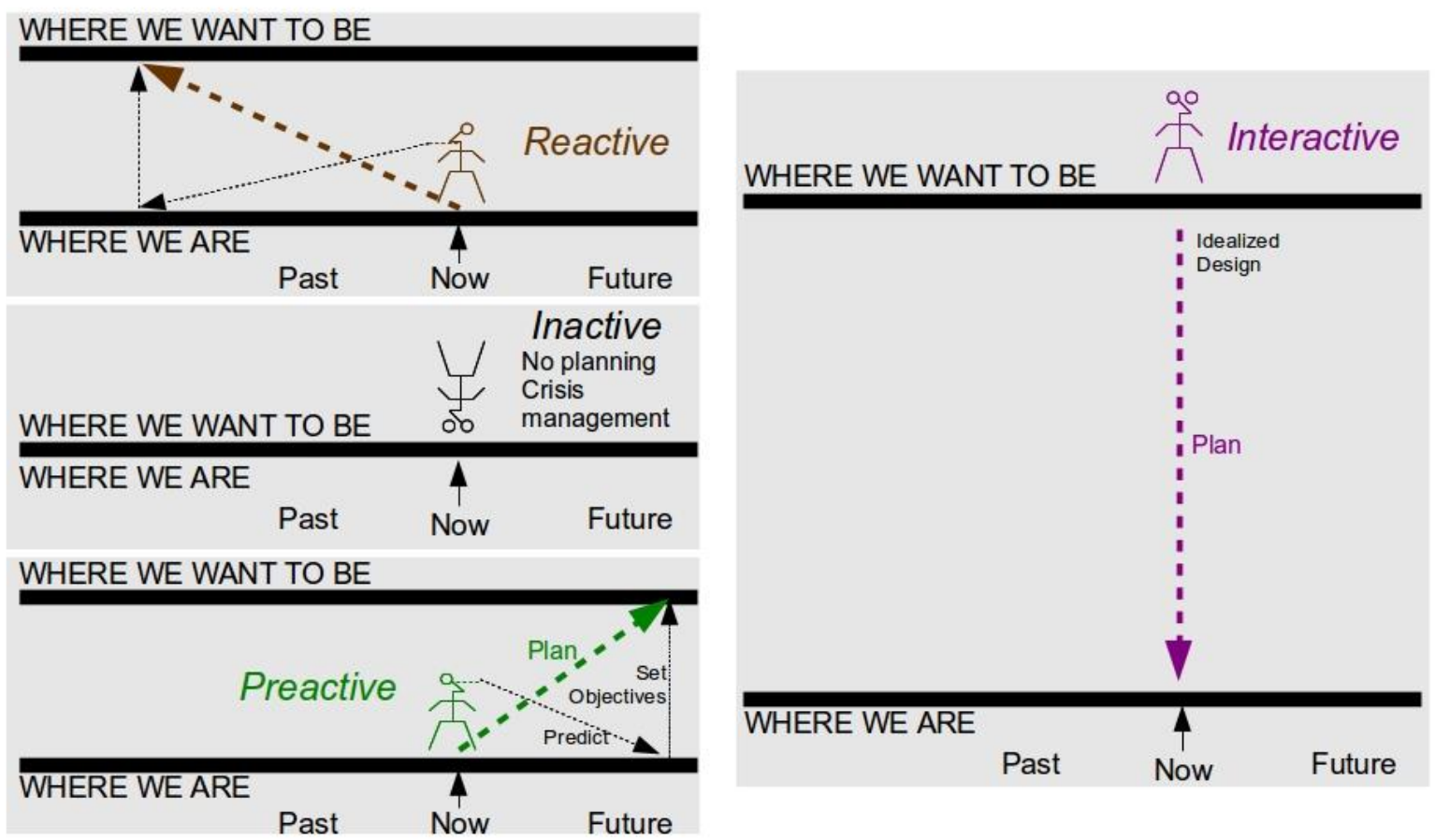

Figure 4: Reactivism, Inactivism, Preactivism, Interactivism

- Reactivists prefer a previous state, and may resist an intervention by trying to return to where they once were, even undoing previous changes;

- Inactivists are satisfied with the way things are, and see any intervention as unlikely to improve their state, with the possibility that conditions could be worse;

- Preactivists believe the future will be better than the present, attempting to predict and prepare for changes within a system, rather than adapting the system to changes in the environment; and

- Interactivists are not willing to settle for the current state of affairs or to return to the past, and will work towards desirable futures by preventing for threats and creating opportunities (Ackoff, 1997).

A change target discord occurs when stakeholders are not given the opportunity to voice their points of view and concerns on the subject. Plans for change are normally explained rationally. Stakeholders may, however objections have due to non-rational (i.e. aesthetic, poetic, political and/or religious) grounds. Dialogue on concerns may lead to learning, so that objections may be reduced to concurrence, if not endorsement. Failure to deal with the nonrational may lead to the having to deal with the irrational, as emotions overcome reason (Hawk, 1996).

\subsection{Resource Scaling Collapse: Supply Side Sustainability}

As systems scale up in size, they may be elaborated in one of two ways: (a) through a structural elaboration, where complicatedness is increased along a flat hierarchy, or (b) through an elaboration of organization, where complexity is increased in a deep hierarchy 
(Allen, Tainter, \& Hoekstra, 1999), shown in Figure 5. In a socio-political system, the flat hierarchy illustrated by the Byzantine empire of fragmented centres was able to sustain for a thousand years by decomplexifying, while the deep hierarchy for the Roman empire collapsed as the intensity of resources was unsustainable at the peripheries far from the centre of Rome.

This pattern is demonstrated in the design of Internet servers, where workloads are distributed across multiple machines. When a network of web servers reaches capacity, the choices are (a) structural elaboration through the addition of more - usually identical machines so that the front end load balancer can distribute requests over the increasingly complicated system; or (b) elaboration of organization through the addition of specialization, e.g. compute-bound requests sent to faster processors and disk-bound requests sent to faster storage devices, in an increasingly complex system.
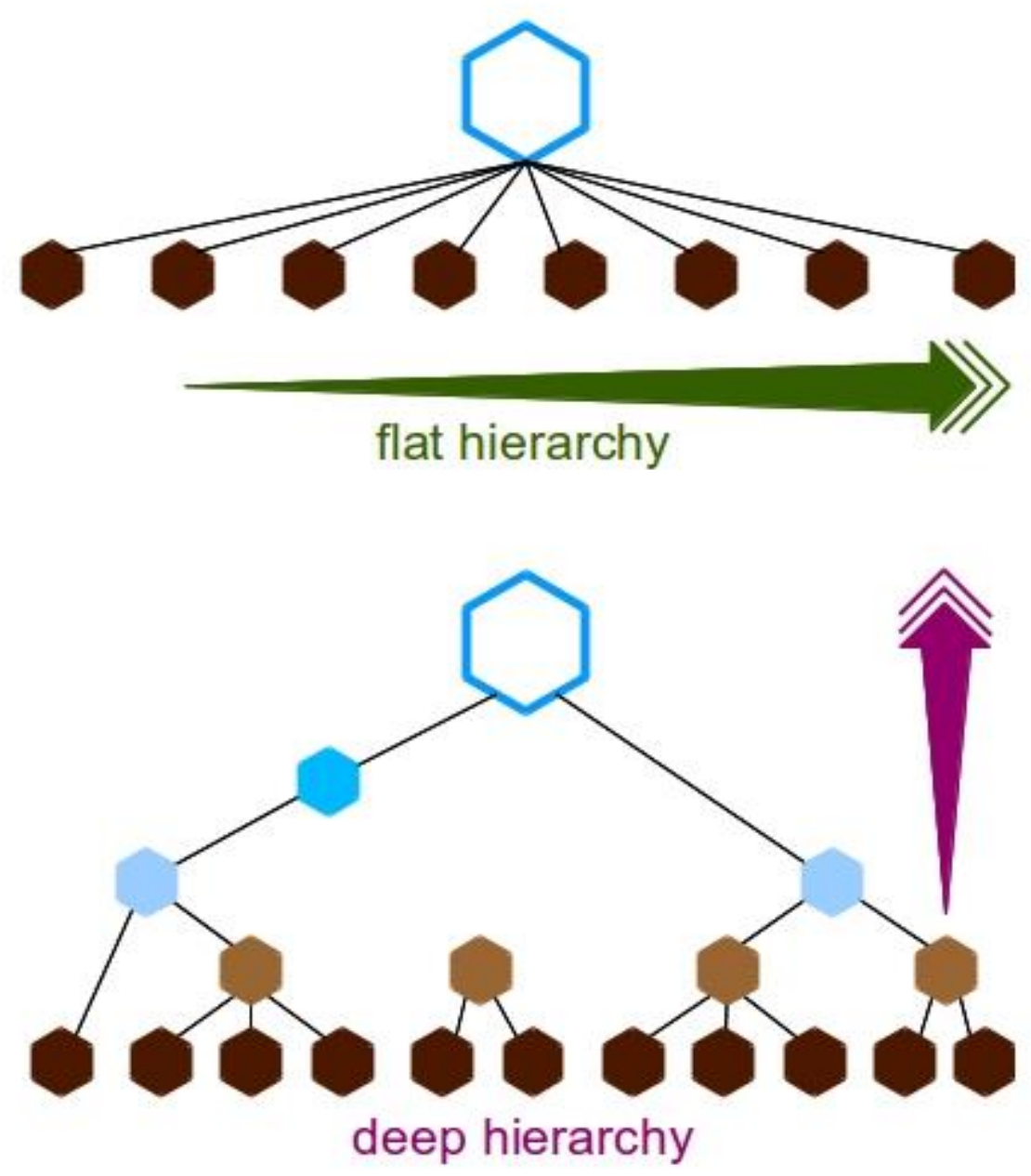

Figure 5: Flat hierarchy, deep hierarchy

The complicated designs represent a low gain pattern, where each resource unit requires consumes less energy, and the flat hierarchy results in greater sustainability (Allen, Allen, Malek, Flynn, \& Flynn, 2009). Think of a server farm of computers based on personal computer technology: each microprocessor operates off household electrical power, and if one unit fails, that workload can be shifted over to another. The complex designs represent a high gain pattern, where the overall server cluster consumes less total energy, and the deep hierarchy operates with greater efficiency. Comparing a mainframe computer to the server 
farm, total electrical power consumption is lower, but if one of the specialized operating units fails, the whole system could fail.

The theory of supply side sustainability advises decomplexifying the deep hierarchies of systems into more complicated flat hierarchies. Resource usage, at the systemic level, is less efficient. However, the long term implications of scaling systems, both up and down, is to preclude collapse.

\subsection{Environmental context shift: Causal texture theory}

Causal texture theory is based on interactions between and of a system and its environment, depicted in Figure 6. In organizations, there are four linkages (represented with " 1 " as the system, and " 2 " as the environment:

- $\mathrm{L}_{12}$ links the planning process, as the system acts on its environment;

- $\mathrm{L}_{21}$ links the learning from the environment back to the system;

- $\mathrm{L}_{11}$ links internal part-part relations (i.e. subsystems interacting with other systems); and

- $\mathrm{L}_{22}$ links environment part-part relations (i.e. parts of the environment interacting with other parts of the environment) (Emery \& Trist, 1965). 


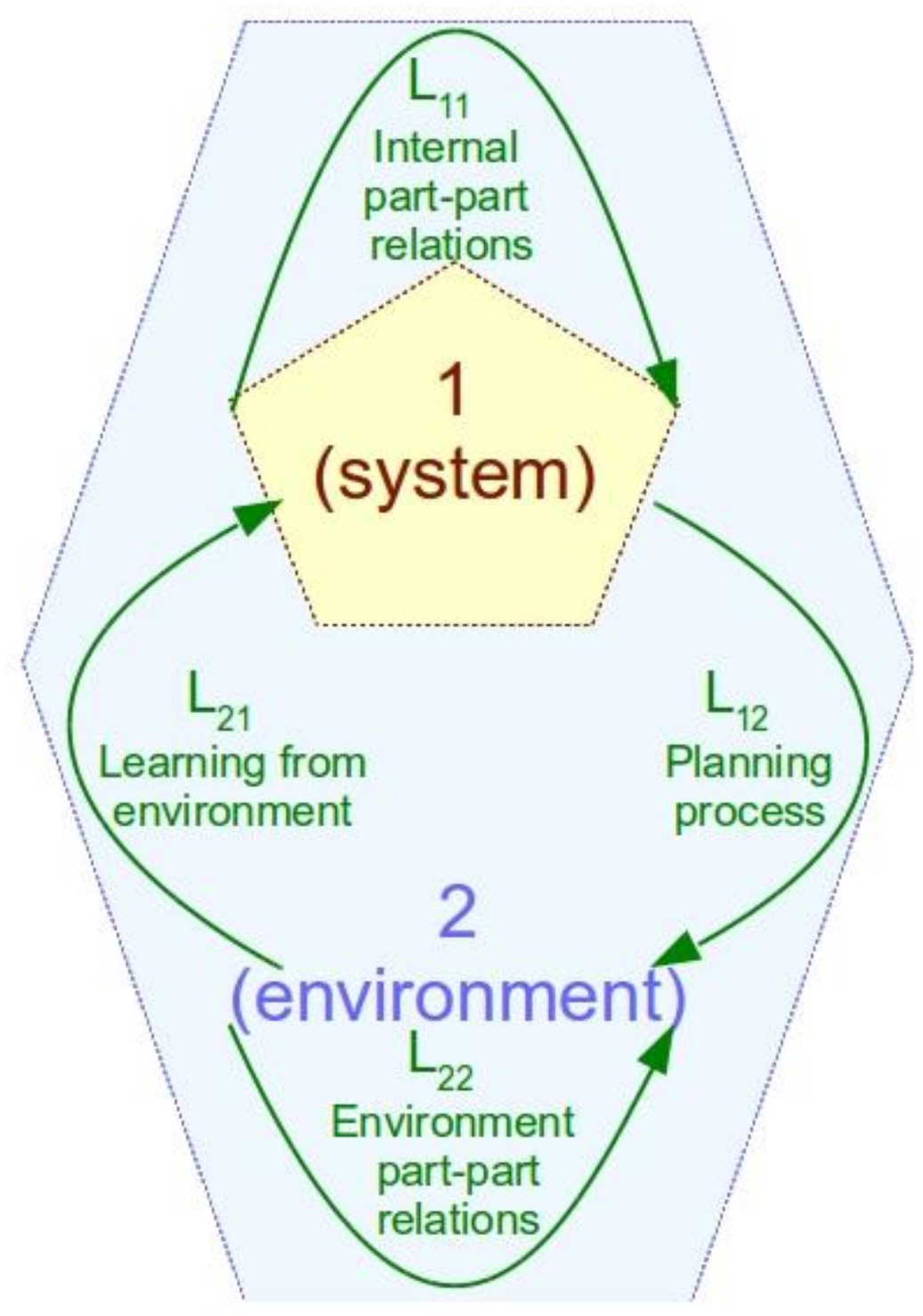

Figure 6: System, environment, linkages

In the field (i.e. the combination of a system and its environment), the causal texture can be described as one of four types:

- Type 1, Random Placid, e.g. a creature lives alone on a flat surface, and there is food everywhere, so when food runs out, the tactic is to move somewhere else.

- Type 2, Clustered Placid, e.g. a creature lives alone on a flat surface, where food is distributed in clumps, so when food runs out, plan to move towards a clump.

- Type 3, Disturbed Reactive, e.g. a creature lives on a flat surface with other competitors, where food is distributed in clumps, so when food runs out, plan to move towards a clump, and if there's a competitor there, move somewhere else.

- Type 4, Turbulent, e.g. a creature and its competitors live on a surface where there is an earthquake, so tactic is to cooperate so that they don't bump into each other. 
In conditions where the causal texture shifts from one type to another, the systems may or may not adapt to the changed conditions. A service system that does not appreciate a persistent shift in the environmental context might not survive the breakdown.

\subsection{Pacing Layers Trap: Coevolution and Learning}

Within a system, there exist layers that change at varying paces. While most would conventionally think about occupants in a home as the system and their house as the environment, a broader view of learning reverses that: the house can be seen as the system that changes in response to its occupants (which represent part of the environment). Buildings learn in six layers, as shown in Figure 7.

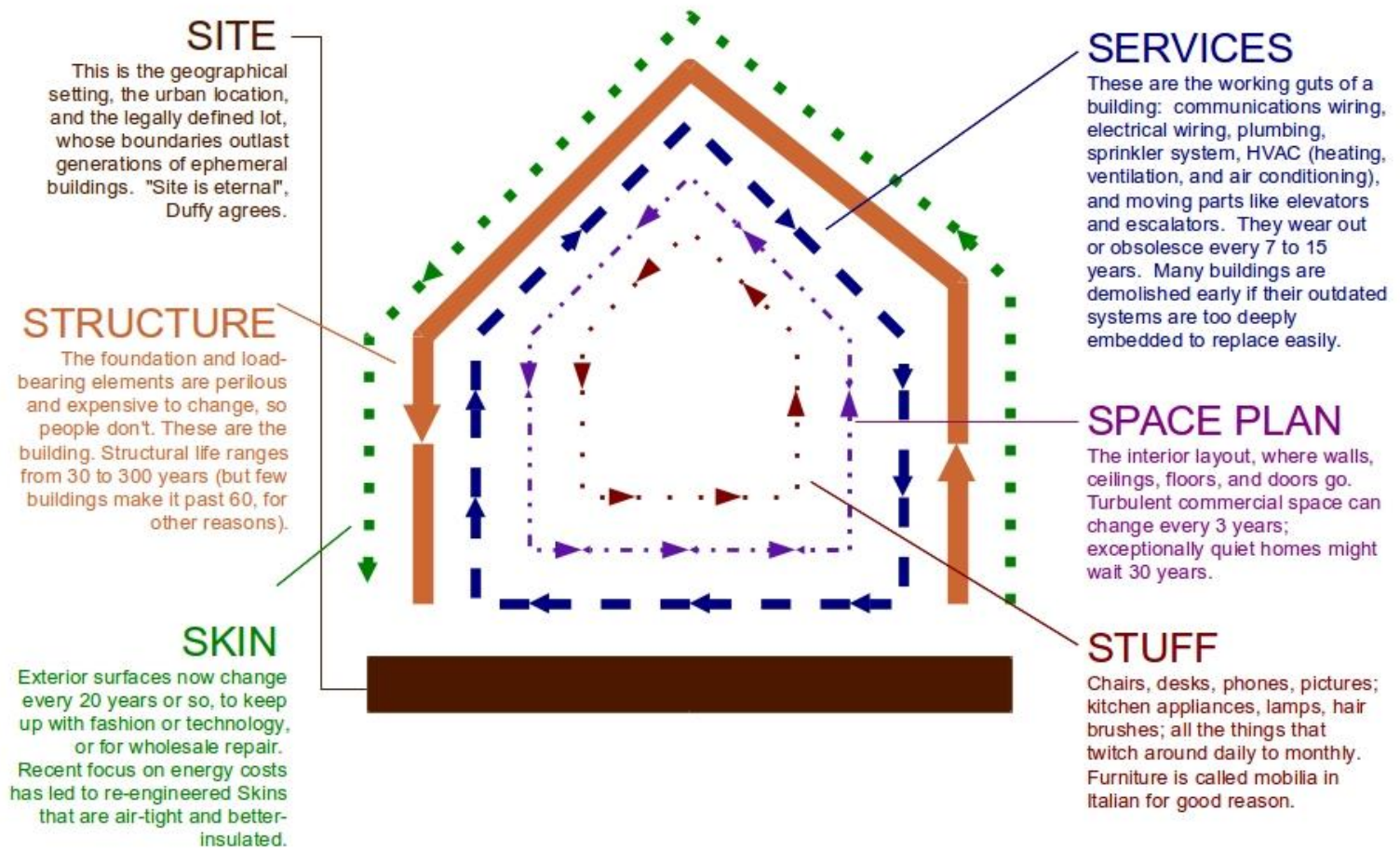

Figure 7: Pacing layers

- The site is slowest changing layer, on which the building is constructed.

- The structure is the next slowest changing layer, as the load-bearing walls that are expensive to modify.

- The skin protects the exterior surfaces from the weather, changing at a rate faster than the structure.

- The services include plumbing and electrical facilities that are constructed inside the structure, that may wear out or obsolesce.

- The space plan are the non-load-bearing walls of the interior layout, that can be changed relatively easily according to needs.

- The stuff, of furniture, changes at a pace most rapidly within the system (Brand, 1994).

Design decisions are often made explicitly about the merits and demerits of placement within layers. As a place to store clothes, a closet could be made part of the space plan, or an 
armoire could be purchased as stuff. If or when the occupant moves out of the house, the closet will stay with the building, whereas the armoire could be taken out by the owner.

A pacing layer is constrained by slower containing layers, and learning or coevolution is easier in the faster contained layers. A breakdown in changing a system may occur by targeting the wrong pacing layer. The faster contained layers are easier to change, but persistent change requires targeting the slower containing layers.

\subsection{Regeneration Failure: Panarchy}

In the Panarchy model, ecosystems have four functions in phases.

- The exploitation ( $r$ for rapid growth) phase, where the scramble of competition sees high usage of energy, leaving potential capacity low, and connectedness low;

- The conservation ( $k$ for sustained plateau or maximum population) phase, where contest competition sees potential as high and connectedness as high;

- The release or creative destruction ( $\omega$ for ending) phase, where potential is low and connectedness is high; and

- The reorganization or innovation ( $\alpha$ for beginning) phase, where high potential and low connectedness represent an opportunity for a transformation (Gunderson \& Holling, 2002; Holling, 2001).

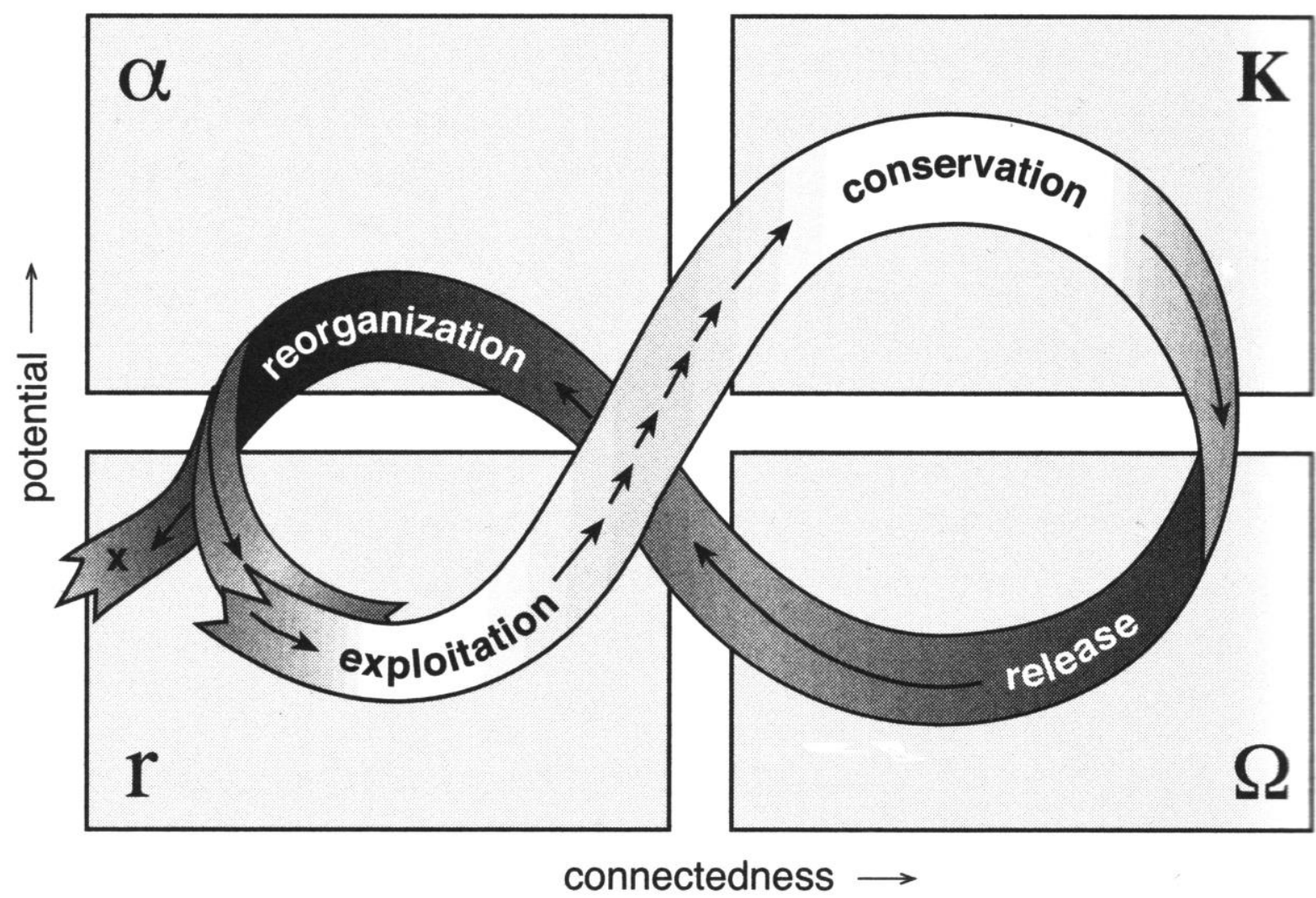

Figure 8: Adaptive cycle loop

The engineering definition of resilience sees disturbed systems returning to their original state. An ecological definition of resilience sees that alternative stable states (or regimes) are possible. Trying to preserve a system in conservation $(\mathrm{K})$ phase when nature presses towards 
a release $(\Omega)$ phase can be counterproductive. Denial results in deferred or failed regeneration.

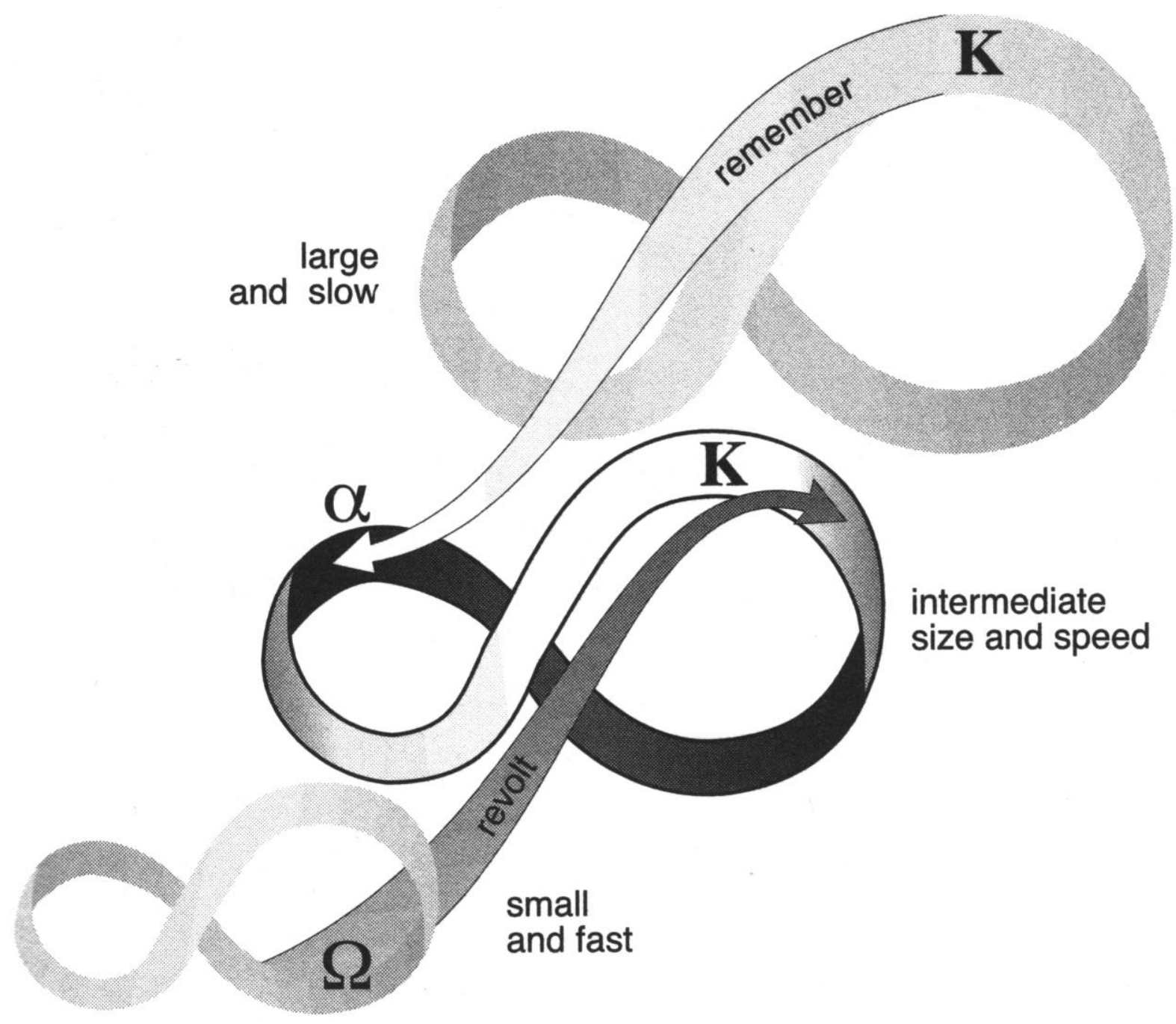

Figure 9: Nested Panarchy cycles

Ecological resilience is high in $\alpha$ phase, and low in $\Omega$ phase. Systems are hard to change when resilience is high. Interventions may be better planned where resilience is low. Release in a smaller and fast system may lead to a "revolt" connection to a system of intermediate size and speed. Conservation in a larger and slower containing system may facilitate renewal in the system of intermediate size and speed through a "remember" connection.

\section{Where Might Collaborations with Systems Thinkers Naturally Co-develop?}

As an alternative to deciphering the meaning in the sample conditions described above, designers might consider collaborating with systems thinkers to improve service systems design. Applying systems thinking, in the form of the systems sciences, requires a broader appreciation defining science. Communications could be improved through the development of a pattern language for services systems. Putting theory into practice, action research methods could provide a platform for shared learning. 
3.1 Systems thinking as broader view of science appreciates episteme, techne and phronesis Science is often associated mostly with episteme (i.e. analytical scientific knowledge). Systems thinking takes a broader view of science to include techne (i.e. technical knowledge) and phronesis (i.e. practical ethics). If episteme is described as "know why" and "techne" is know how (embodied both in individuals and in groups), then phronesis may be known as "know when, know where, know whom". Aristotle placed phronesis - as a pursuit of values in practice based on judgement and experience - as a virtue higher than either episteme (a pursuit of uncovering universal truths) or techne (a pursuit of instrumental rationality towards a conscious goal. Designers could be led to similarly elevate phronesis.

\subsection{A pattern language for service systems makes a shared vocabulary more concrete}

Pattern languages originated in built environments (i.e. buildings and towns) through the research of architect Christopher Alexander. They were adapted for use in software development by the Hillside Group: "Patterns and Pattern Languages are ways to describe best practices, good designs, and capture experience in a way that it is possible for others to reuse this experience". A canonical form for patterns includes a pattern name, aliases, problem, context, forces, solution, resulting context, rationale, known uses and related patterns (Coplien 1995),

To communicate the reasoning and motivations for design choices in service systems, designers and systems thinkers - potentially driven by members of the systems engineering community - could embark on a journey to develop a shared pattern language.

\subsection{In collaborations, action research methods could be a shared platform for learning}

In a practice-based, rather than purely theoretical approach, learning about how to improve service systems designs could be a collaborative project by designers and systems thinkers using action research. "Action research, itself, constitutes a process wherein researchers participate in studies both as subjects and objects with the explicit intention of bringing about change through the research process" (Raelin, 1999). The action research cycle, originating from the work of Kurt Levin, has been refined with a description of a startup, and then six phases:

0. Development of a client-system infrastructure, including the definition of the governing group for regulation of the learning cycles.

1. Diagnosis: Identifying or defining a problem.

2. Action Planning: Considering alternative courses of action to solve a problem.

3. Action Taking: Selecting a course of action.

4. Evaluating; Studying the consequences of an action.

5. Specifying learning: Identifying general findings (Susman \& Evered, 1978). 


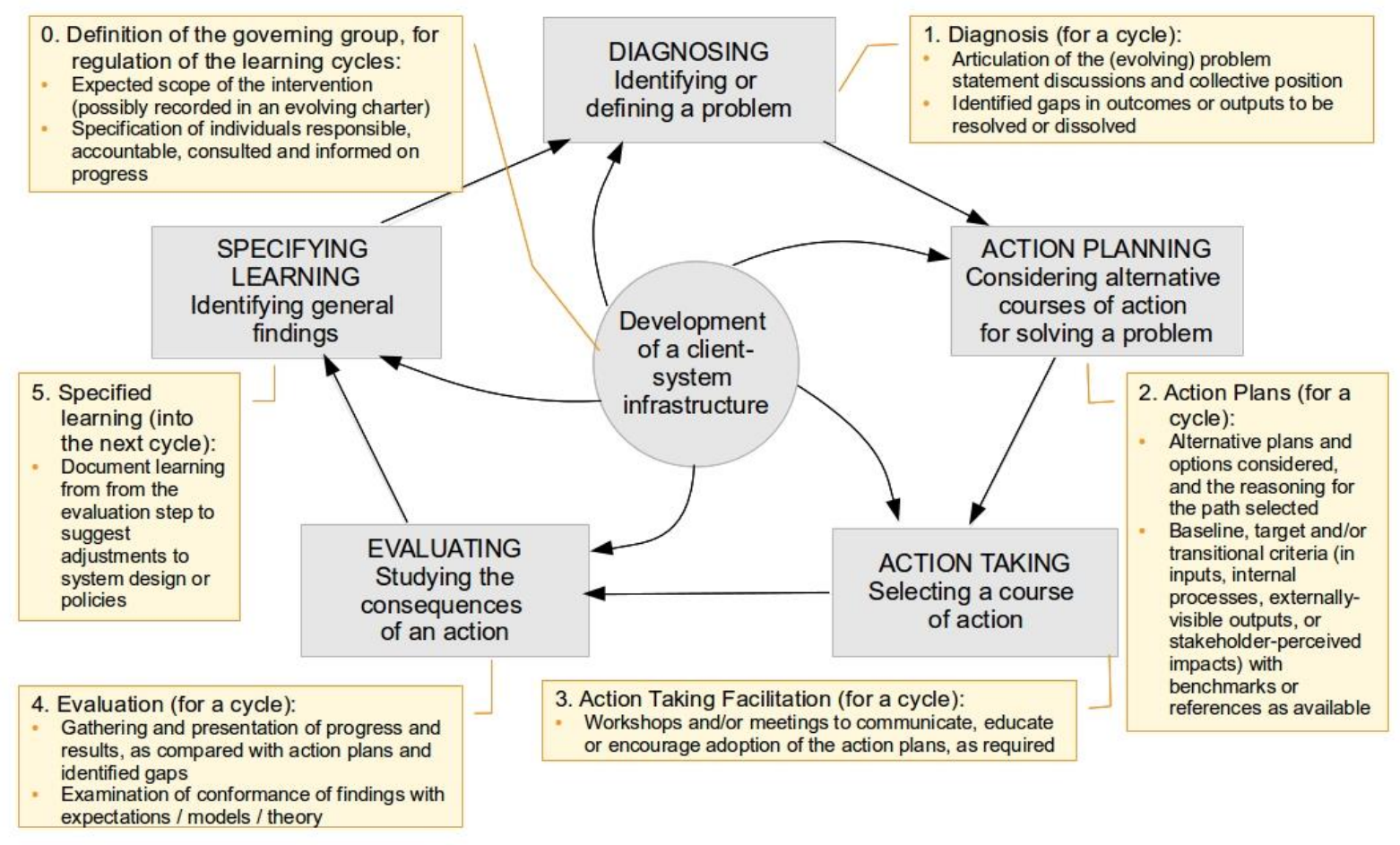

Figure 10: Action research cycle

In documenting action plans, it is as important to record reasons for actions not taken, as much as for actions taken. Action research is a systemic approach, and thus the conditions relevant to the problem at one point in time may or may not receive the same weight and priorities at a later time.

\section{Systems Thinking Appreciates the Design of the Inquiring System}

If designers and systems thinkers are to work together, development of the joint work may benefit by an understanding of the selected inquiring system. In the design of inquiring systems, five ways of knowing - each associated with a school of philosophy - are recognized: (a) inductive-consensual (Locke); (b) analytic-deductive (Leibniz); (c) multiple realities (Kant); (d) dialectic (Hegel); and (e) multiple perspectives. Designers who have not directly engaged the systems thinking community may be puzzled as to why definitions of the field have not standardized, while that community continues to endure with solidarity.

Our survey can be summarized in a few brief but critical propositions:

- Every science is to be found within every other.

- Every model presupposes every other model.

- Every problem is to be found within every other problem.

The recognition of an use of these insights or principles is precisely what characterizes or constitutes unbounded systems thinking, or UST (Mitroff \& Linstone, 1993).

As designers increasingly work towards improving service systems, they may find absorbing the breadth and depth of books on systems thinking insufficient. The spirit of continual learning and framing is deep in the heritage of the systems thinking community. 
Interaction and engagement between designers and systems thinkers can be a productive path forward.

\section{David Ing}

Visiting scholar at Aalto University

Research fellow at Hull University (UK)

Email address: coevolving@gmail.com 


\section{References}

Ackoff, R. L. (1981). Creating the corporate future: plan or be planned for. New York: John Wiley and Sons.

Ackoff, R. L. (1997). Systems, messes and interactive planning. In E. L. Trist, H. Murray, \& F. E. Emery (Eds.), The social engagement of social science: The socio-ecological perspective (Vol. 3). Philadelphia: University of Pennsylvania Press.

Allen, T. F. H., Allen, P. C., Malek, A., Flynn, J., \& Flynn, M. (2009). Confronting economic profit with hierarchy theory: The concept of gain in ecology. Systems Research and Behavioral Science, 26(5), 583-599.

Allen, T. F. H., Tainter, J. A., \& Hoekstra, T. W. (1999). Supply-side sustainability. Systems Research and Behavioral Science, 16(5), 403-427.

Brand, S. (1994). How buildings learn: What happens after they're built. New York: Viking.

Brown, T. (2008). Design thinking. Harvard Business Review, 86-92(6), 84.

Christakis, A. N. (2006). A retrospective structural inquiry of the Predicament of Humankind. In J. P. van Gigch \& J. McIntyre-Mills (Eds.), Rescuing the Enlightenment from itself: Critical and systemic implications for democracy (Vol. 1, pp. 93-122). Springer.

Churchman, C. W. (1971). The design of inquiring systems: Basic concepts of systems and organization. New York: Basic Books.

Coplien, J. (1995). Organizational patterns. In J. Coplien \& D. Schmid (eds.), Pattern Languages of Program Design, pp. 183 - 237. Boston: Addison-Wesley.

Cross, N. (1982). Designerly ways of knowing. Design Studies, 3(4), 221-227.

Cross, N. (2001). Designerly ways of knowing: Design discipline versus design science. Design Issues, 17(3), 49-55.

Cross, N. (2007). From a design science to a design discipline: Understanding designerly ways of knowing and thinking. In R. Michel (Ed.), Design research now (pp. 41-54). Basel: Birkhäuser.

Emery, F. E., \& Trist, E. L. (1965). The causal texture of organizational environments. Human Relations, 18(1), 21-32.

Gharajedaghi, J. (2007). Systems thinking: Managing chaos and complexity : a platform for designing business architecture. Burlington, MA: Morgan Kaufmann.

Gunderson, L. H., \& Holling, C. S. (2002). Panarchy: Understanding transformations in human and natural systems. Washington, DC: Island Press.

Hawk, D. L. (1996). Relations between architecture and management. Journal of Architectural and Planning Research, 13(1), 10-33.

Holling, C. S. (2001). Understanding the complexity of economic, ecological, and social systems. Ecosystems, 4(5), 390-405. doi:10.1007/s10021-001-0101-5

IBM. (2010). The world's 4 trillion dollar challenge: Using a system-of-systems approach to build a smarter planet (No. GBE03278-USEN-02). Retrieved from: ibm.com/services/us/gbs/bus/html/ibv-smarterplanet-system-of-systems.html

IfM, \& IBM. (2008). Succeeding through service innovation: a service perspective for education, research, business and government. Cambridge, UK: University of Cambridge Institute for Manufacturing. Retrieved from: ifm.eng.cam.ac.uk/ssme

Ing, D. (2008). Offerings as commitments and context: Service systems from a language action perspective. In Proceedings of the 12th International Conference of the UK System Society. Oxford, UK.

Ing, D. (2013). Rethinking systems thinking: Learning and coevolving with the world. Systems Research and Behavioral Science, 30(5). doi:10.1002/sres.2229

Macaulay, S. (1963). Non-contractual relations in business: A preliminary study. American Sociological Review, 
$28(1), 55$.

Mitroff, I. I., \& Linstone, H. A. (1993). The unbounded mind: Breaking the chains of traditional business thinking. New York: Oxford University Press.

Normann, R. (2001). Reframing business. New York: Wiley.

Normann, R., \& Ramirez, R. (1994). From value chain to value constellation: Designing interactive strategy. Chichester, UK: Wiley.

Normann, R., \& Ramírez, R. (1989). A theory of the offering: Toward a neo-industrial business strategy. In C. C. Snow (Ed.), Strategy organisation design, and human resource management (pp. 111-128). Greenwich, CT: JAI Press.

Parhankangas, A., Ing, D., Hawk, D. L., Dane, G., \& Kosits, M. (2005). Negotiated order and network form organizations. Systems Research and Behavioral Science, 22(5), 431-452. doi:10.1002/sres.717

Pourdehnad, J., Wexler, E. R., \& Wilson, D. V. (2011). Systems \& design thinking: A conceptual framework for their integration. Proceedings of the 55th Annual Meeting of the ISSS - 2011, Hull, UK, 55(1). Retrieved from journals.isss.org/index.php/proceedings55th/article/view/1650

Raelin, J. (1999). Preface to special issue on the action dimension in management: Diverse approaches to research, teaching and development. Management Learning, 30(2), 115-125.

Ramírez, R., \& Wallin, J. (2000). Prime movers: define your business or have someone define it against you. Chichester, UK: Wiley.

Rittel, H. W., \& Webber, M. M. (1973). Dilemmas in a general theory of planning. Policy Sciences, 4(2), 155169.

Spohrer, J. C., \& Maglio, P. P. (2010). Toward a science of service systems: Value and symbols. In P. P. Maglio, C. A. Kieliszewski, \& J. C. Spohrer (Eds.), Service science:Research and innovations in the service economy (pp. 157-194). Boston, MA: Springer.

Susman, G. I., \& Evered, R. D. (1978). An assessment of the scientific merits of action research. Administrative Science Quarterly, 23(4), 582-603.

Winograd, T. (1986). A language/action perspective on the design of cooperative work. In Proceedings of the 1986 ACM Conference on Computer-Supported Cooperative Work (pp. 203-220). Austin, TX: ACM.

Winograd, T. (2006). Designing a new foundation for design. Communications of the ACM, 49(5), 71-74.

Winograd, T., \& Flores, F. (1986). Understanding computers and cognition: A new foundation for design. Norwood, NJ: Ablex. 